\title{
Thinking Principles for the Quantum Leader
}

Just as different times call for different leaders, different times also call for different leadership skills. Quantum physicist David Bohm famously said, "All the problems of the world are problems of thought. If we want to change the world, we must change the way we think." This reminds us that the most important leadership skills that must match the times are the leader's thinking skills and habits. For our new Quantum Age, those must be thinking skills and habits that spark constant innovation, maximize human potential, can thrive on uncertainty and rapid change, and that can recognize and benefit from the interconnectivity of events, people, and human needs.

Everything I have written in this book so far has been about the radical shift in mindset required to structure and lead organizations adapted to thrive in the twenty-first century, but here below are some specific thinking habits to guide leaders.

\section{INTUITION/CREATIVE INSIGHT}

By intuition I am not referring to the quick, gut-level instinct that many of us experience as an unreflective sense of knowing what is best to do, or what is the best decision to make. Such gut-level instinct can be a very effective way to make spur-of-the-moment decisions or choices where quick action is needed, or when there seems no available, logical stream of thought for making a choice. But as Daniel Khaneman pointed out in

(C) The Author(s) 2022

D. Zohar, Zero Distance, https://doi.org/10.1007/978-981-16-7849-3_14 
his Fast and Slow Thinking, gut instinct can often be wrong, or mistaken. It is really a kind of "thinking without thinking," and can err, where "thinking something through carefully" would lead to a very different choice or decision.

When I write here about intuition as a source of creative insight, I am referring to the long, slow, ruminative process that can result in a sudden breakthrough, or creative insight that offers an entirely new way of understanding or seeing something. This, too, comes with a sudden "aha!" sense of surprise, a sudden flash of understanding or vision that seems "to come out of nowhere," but is accompanied by a sense of certainty far deeper and more sweeping than any certainty arrived at by logical, step-by-step thought. Indeed, that kind of logical teasing out of the "reasoning" that backs up the sudden flash of creative insight may then take hours, weeks, or years fully to work out. It may be the program for an entire lifetime's work fully to work out what came to us in that moment of insight.

This is a slower kind of intuition that came to Newton and Einstein in physics, to Mozart and Beethoven in music, to great painters like Van Gogh and Picasso, and in their cases we call it "genius." But perhaps less sweeping instances of it lay behind the breakthrough work of innovators like Steve Jobs, Mark Zuckerberg, and Elon Musk, great business thinkers and leaders like Frederick Taylor, Peter Drucker, Jack Welch, Jack $\mathrm{Ma}$, and Zhang Ruimin. And smaller instances of it occur in daily life to gifted teachers, managers, designers, gardeners, parents, and of course, very commonly, to children. Indeed, I believe that this kind of intuitive creativity is available to us all as humans if only we know how to preserve and nurture it in ourselves. It is a very familiar skill of quantum leaders, and can be nurtured by certain qualities of mind. The quantum leadership principles that help us generate creative insights are:

- Celebration of Diversity: Many studies in neuroscience have shown that people who take in more data, who have a wider, richer range of knowledge and experiences on which the unconscious mind can ruminate and which it can see new relationships between, have more breakthrough, creative insights. Mervyn King, the former governor of the Bank of England, says about creative decision-making, "In the ordinary business of life, where we are constantly confronted with 
unique situations, we need a pluralism of approaches and models."1 Thus constant feeding of our minds, cultivating ourselves by seeking new and unfamiliar experiences or reading widely outside our usual field of interests, provides "food for creative thought." King and his coauthor John Kay also point out that collaborative thinking in groups can further enrich the range of data and experience on which we can draw. "Successful decision making under uncertainty," they say, "is a collaborative process....We make better decisions in groups, because in a radically uncertain world the group holds more information than any one individual." 2

- Openness (Receptivity): If creative insights are to arise from the unconscious mind, we must still the "monkey mind" of busy daily activity and its requirement of focused, left-brain attention. We need to sit quietly, without distraction, and simply open ourselves to whatever the deeper mind might be speaking to us. Engaging in a meditation practice can be very effective. For those who find it difficult simply to sit still and be receptive, taking our "mind off things" by doing something more active that occupies concentration but has nothing to do with daily tasks or the problem we are trying to solve-like playing a game of golf, going for a walk, preparing a meal, or listening to music-can free the more intuitive mind to surface. There are many reported instances of people getting their creative breakthroughs during deep, dreaming sleep.

- Spontaneity/Openess: When we are spontaneous, we are open to the moment and whatever it brings, not allowing our minds to dwell on other things. Our full attention is on the "now." Thus, while sitting quietly, we should, as best possible, simply be in a state of spontaneous awareness.

- Holism: Again, studies in neuroscience show that creative people have a greater tendency or capacity to see relationships between apparently unrelated thoughts or events, the associations between 'this' and 'that'. And it is the sudden insight that "this" is related to "that" that leads to the emergent "aha!" experience of new discovery. If, as a normal part of our daily understanding of situations and events, we practice looking for the relationships at play,

${ }^{1}$ John Kaye and Mervyn King, Radical Uncertainty, p. 412.

2 Ibid., p. 416. 
we strengthen the unconscious mind's ability to see ever more relationships.

- Asking Fundamental Questions: People who ask more questions train their attention to look for more answers. Behind every act of creative intuition, there is a mind that asks "Why?" or "How?" or "What?" Such people are constantly, often unconsciously, searching for more new and deeper understanding.

- Ability to Reframe: By its very definition, a creative insight gained through intuition is a radical reframing of previous understanding.

\section{Reflective Thinking}

In the previous chapter, I outlined a Reflective Practice that helps us better to live by the twelve principles of quantum leadership. We saw there that an ability to stand back from a situation or our own emotions and view them with a more cool detachment is critical to reflective thinking. Reflective thinking also helps us to understand what things mean, why they have happened, and thus what conclusions can be drawn from them. It helps us to understand why ourselves or others behave as we do, or make the decisions that we do, and thus opens an opportunity to engage in more beneficial behavior or to make better decisions. Reflective thinking also helps us to select the relevant data from a mass of information or a very complex situation. The quantum leadership principles that help us do reflective thinking are:

- Self-Awareness: Our own immediate involvement in a situation, or the concentration with which we have been focusing on a problem, can prevent us from standing back and reflecting on it. Strong emotion or strong commitment to a particular way of thinking about or doing something makes us part of the problem. Creative reflection becomes possible only when we stand back and become aware of our own involvement, of the assumptions, biases, or emotions that we have been harboring. Thinking about the role these have played is an important part of the reflective process.

- Asking Fundamental Questions: Using the distance gained by standing back, we can now ask why we or others displayed the emotions or commitments that we did. What was it about the situation that made us angry? Do we always get angry in such situations? 
Why? Why do we behave as we do when we are angry and what contribution did that make to the situation? What does this say about us? Why were we or others so certain of some conviction? Are we too quick to rush to judgments or conclusions? Did we consider the wider context, the bigger picture? Did we look at all the arguments or possibilities critically? Why not? Look at the root of the problem. What really caused it? How might it be looked at differently?

- Humility: If we think we know best, and have all the answers, we will not have the receptivity and openness necessary for breakthrough insight. The capacity for self-criticism and an ability to recognize our own role in a negative situation is critical to sound reflection. We must have the humility to admit that we might have been wrong and then to ask "why?". And, of course, listening to others nourishes reflective thinking.

- Celebration of Diversity: Having a wide and varied range of knowledge and experience to draw on makes reflection much more creative.

\section{Contextual Thinking}

In setting forth the key components of strategy in his Art of War, Sun Tzu advises "Know your position." He explains that this means the full context of the forthcoming battle-the climate, conditions on the ground, the motives and psychological state of your opponent, and the relationship of your position to the positions of the others. ${ }^{3}$ Similarly, Mervyn King and John Kaye, writing about decision-making in the face of radical uncertainty, offer one piece of, primary, advice: "Always ask 'What's going on here?" He points out that there is no one most rational decision to make in the face of radical uncertainty. Instead, he argues there are many ways to be rational, and which one to choose depends upon the overall context within which situation is set. Thus, always ask: What is going on here, in this context?

Quantum physics underpins the advice of Sun Tzu and Mervyn King by reminding us that we can never know or understand a thing or a situation unless we know its full context, that is, know what it is in relation to

${ }^{3}$ Sun Tzu, The Art of War, Chapter 1. 
and thus what forces are at play in influencing it. The quantum leadership principle of most importance for contextual thinking is of course:

- Holism: This is realizing that everything is entangled with everything, that our company is not an island, and making ourselves aware of the network of relationships, and thus influences, of which our company is a part - the physical and climatic environment, political and economic conditions, public health, customers, partners, employee capacity, morale, and motivation, the competition, etc.everything that comprises the dynamic system of which we are a part. Contextual thinking is, effectively, systems thinking. So when making any strategic decision, we must always ask, "What are all the factors and actors at play in the total system of which our company is a part? What is the influence each is having on company performance, and is there any pattern to our response?"

\section{Critical Thinking}

This is having the capacity for independent thinking and judgment; the power to discriminate good arguments from poor ones, and to assess what is and is not relevant. Critical thinking is also the ability to surface our own assumptions and biases, or the assumptions and biases at play in a strategy or a line of thinking. And it is the ability to grow beyond or change these assumptions as necessary. The quantum leadership principles to follow to develop sound critical thinking are:

- Self-Awareness: Having an ability to recognize our own assumptions and biases, and an ability to see what role our own thinking or behavior might be playing in a bad situation or poor strategy.

- Field-Independence: We also must have the ability to stand outside the assumptions of our group or team and see how these might be having negative or undesired influence on behavior or strategy. We must be willing to question authority, our own and that of others.

- Ability to Reframe: Once we have recognized the assumptions and biases that have led to a poor strategy or situation, we must be willing to "think again," to look at the problem or situation from a new perspective. 


\section{Adaptive Thinking}

The one thing that all leaders can be certain of today is that the future is radically uncertain. We simply don't know what may come at us tomorrow. As Heather McGowan and Chris Shipley say in their Adaptive Advantage, "To thrive in the future of work, we must be agile and resilient, adept at both learning and unlearning, to continuously adapt to change." 4 The quantum leadership principles that most underscore adaptive thinking are:

- Spontaneity: Spontaneity is the very essence of agility. Being in, and responsive to, "now." We must recognize that what worked in the past may now be irrelevant, and not be too attached to plans we have made for the future. Act as this moment requires us to act.

- Celebration of Diversity: Again, the more knowledge and experience we have, the better equipped we are to deal with unexpected situations or events in an agile way. We must cultivate a love of learning and realize that learning is the ongoing work of a lifetime.

- The Positive use of Adversity: The greatest enemy of adaptive thinking and behavior is fear, a fear of losing what we have, a fear of letting go, a fear of the unknown. Such fears follow from a lack of trust in our own abilities and resilience, a lack of trust that life and situations have their own logic, and thus a tendency to cling to the familiar. They make us risk-averse, and any strategy in the face of uncertainty will necessarily involve risk. The positive use of adversity requires a "ready for anything" confidence and an openness to, ideally even a thrill in the face of, new challenges.

- Ability to Reframe: And, of course, the agility to adapt in the face of the unexpected requires an ability to change our perspective, to see events and situations in a new way, an ability constantly to reinvent our own mindset and thus to put in place new strategies.

${ }^{4}$ Heather E. McGowan and Chris Shipley, The Adaptive Advantage, p. 97. 


\section{Moral Maturity}

Moral maturity is not something commonly thought of as a leadership skill or even as a leadership requirement, and yet it is something we recognize and prize in the great leaders who have possessed it and, I argue, is a must have for the quantum leader. This quality reflects the extent to which we are sensitive, thoughtful, responsible, and values-driven in our actions, decisions, and relationships, the extent to which we possess integrity. It reflects our ability to make and keep to commitments, and the depth of those commitments themselves. Also, it depends upon our ability to be open-minded and fair, to have a sense of the role we play as a leader and to fulfill it. Morally mature leaders are trustworthy, they inspire confidence and faith in those whom they lead, and their employees (or citizens) don't just admire or respect them, they love them. Thus they bring out the very best in others. I also believe that a morally mature quantum leader has a basic, guiding intuition that there is a moral order built into the universe itself and that this must be reflected in our behavior and decisions. Acquiring moral maturity requires life-long self-cultivation and is what we mean by building our "character." Thus, it depends upon practicing and living by all twelve of the principles of quantum leadership.

Open Access This chapter is licensed under the terms of the Creative Commons Attribution-NonCommercial-NoDerivatives 4.0 International License (http:// creativecommons.org/licenses/by-nc-nd/4.0/), which permits any noncommercial use, sharing, distribution and reproduction in any medium or format, as long as you give appropriate credit to the original author(s) and the source, provide a link to the Creative Commons license and indicate if you modified the licensed material. You do not have permission under this license to share adapted material derived from this chapter or parts of it.

The images or other third party material in this chapter are included in the chapter's Creative Commons license, unless indicated otherwise in a credit line to the material. If material is not included in the chapter's Creative Commons license and your intended use is not permitted by statutory regulation or exceeds the permitted use, you will need to obtain permission directly from the copyright holder.

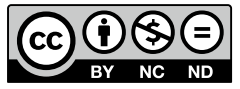

